International Journal of Publication and Social Studies

$\operatorname{ISSN}(e): 2520-4491$

$\operatorname{ISSN}(p): 2520-4483$

DOI: $10.18488 /$ journal.135.2021.61.34.41

Vol. 6, No. 1, 34-41.

(C) 2021 AESS Publications. All Rights Reserved.

URL: wrw.aessweb.com

check for
updates

\title{
EXAMINING THE ACADEMIC AND NON-ACADEMIC CORRELATES OF STUDENT RETENTION
}

\author{
Danebeth Tristeza \\ Glomo-Narzoles ${ }^{1+}$ \\ Donna Glomo- \\ Palermo $^{2}$
}

\author{
'University of San Agustin, Iloilo City, Philippines. \\ Email:dgnarzoles@gmail.com Tel: +639493651836 \\ 'Iloilo City Community College, Iloilo City, Philippines. \\ Email:dtgpalermo@gmail.com Tel:+639957663310
}

Theck for updates

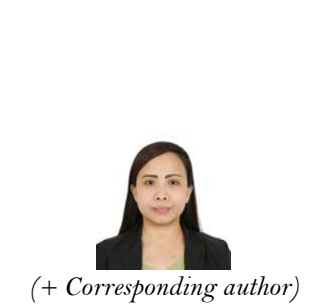

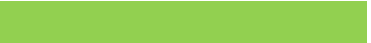

Article History

Received: 6 January 2021

Revised: 25 January 2021

Accepted: 8 February 2021

Published: 22 February 2021

\section{Keywords}

Student retention

Academic interventions

Student support

Withdrawal from the university Drop-outs.

\begin{abstract}
This study was conducted to verify the reasons of students who had withdrawn or discontinued their studies. Academic and non-academic correlates of student retention were identified through the reasons provided by the students in the Withdrawal/Dropping Out Forms which are available at the Registrar's Office. Moreover, telephone calls were done to further discuss the reasons for leaving the university. Majority of students who had withdrawn are males. In terms of program enrolled, there are many business students who dropped out from the university, followed by the international studies, engineering, computing, and lastly, the graduate students. Moreover, majority of those who dropped out are married, followed by single, divorced, and others who did not mention their status. On the other hand, there were more working students who had withdrawn from the university compared to nonworking students. Among the reasons cited for leaving the university, the top five are experienced health-related problems, did not have enough money to continue, and accepted a fulltime job, conflict between demands of job and university, and visa problems. Reasons that were not cited at all are on the program/institutional issues such as dissatisfied with academic performance, could not connect classroom to the outside world, achieved academic goals, dissatisfied with the class size, dissatisfied with the learning environment, dissatisfied with the quality of teaching, and inadequate academic support.
\end{abstract}

Contribution/ Originality: This study contributes to the existing literature on the possible causes or factors of student retention. Finding answers to this question might shed light on how to decrease the gap between university enrollment and degree completion which is a common problem faced by a lot of higher education institutions.

\section{INTRODUCTION}

Developments in society and higher education over the last few years have contributed to the effort of institutions of higher education to confront the problem of student retention. These developments may include the changing structure of the economy, in which there has been a decrease in the availability of jobs that do not require skills associated with a university education and the increasing accessibility of higher education, among others. Changing students' beliefs and expectations of quality and affordable tertiary education has posed tremendous challenge to the higher education institutions (HEIs). As universities have been exploring strategies to advance student retention in HEIs, studies and surveys about this important subject, participated in by external consultants and academicians, have shown that various factors contribute to student retention, from economic to psychological 
issues (Sagenmüller, 2018).

Marsh (2014) revealed that the main reason for student withdrawal was one of isolation; they had failed to be engaged by the university, the department, or their fellow students. This is most evidenced by the students' low attendance at classes and social events, which ultimately resulted in withdrawal from the course.

A study conducted by a university in Australia found out that students leave the university because of the following reasons: personal difficulties, which are related to health, finance, family, work and difficulty adjusting to the university life, or having friends; academic issues, including lack of academic preparation, low academic performance, or other specific skills needed in the program chosen; employment status of the students in which part-time students are less likely to continue their studies compared to full-time students; having the wrong choice of the program/university which may reflect the poor information provided prior to enrolment; and some other issues like loss of interest in the program, not being able to manage time and workload demands, and dissatisfaction with the academic experience, curriculum, or quality of teaching (King, 2017).

According to Yamnikar (2006) all of the students withdrawing from the first year are full-time students, very few part-time students withdraw, perhaps due to the fact that they are being sponsored by employers. Failure to complete will almost certainly affect their employment and, as a result, part-time students only tend to withdraw if their employment conditions change. Moreover, Yamnikar's investigation revealed that the principal reason for student withdrawal was one of isolation; they had failed to be engaged by the university, the department, or their fellow students. This presented itself most notably in a lower level of attendance at time-tabled classes and social events, which fed the downward spiral of disillusionment which had started the moment they enrolled in the department, ultimately resulting in withdrawal from the course.

Apparently, the university plays an integral part in attaining a desirable student retention rate. This has been corroborated by Kinzie and Kuh (2004) who underscored that the sharing of responsibility for educational quality and student success is woven into the tapestry of educationally effective institutions. A review of the student success and retention-focused accomplishments reveals the significance of effective and efficient collaboration among faculty, staff, and administration in developing effectual initiatives and engendering positive outcomes for students and the institution. While each of the aforementioned initiatives certainly demand the contributions of multiple constituents, it is important to note the central role played by faculty members not only in these initiatives taken individually, but perhaps most critically, in the comprehensive effort to provide for student success and retain students at this institution.

The proximity between faculty members and students on a daily basis in teaching, research, and advising capacities allows for members of the faculty to have unparalleled influence on the lives of students, an influence that some faculty members often underestimate. With institutional empirical data and from theoretical perspectives, factors or barriers may be identified so as to provide clear analysis and pro-active strategies that could possibly work to reduce alarming poor retention rates.

Embedded within this investigation is an underlying question, that is, should the university which encounters issues on student retention look into possible causes or factors or should it dig deeper in order to address the root causes of the issue? Finding answers to questions about this that might shed light on how to decrease the gap between university enrollment and degree completion, a problem faced by a lot of HEIs. Hence, this study was conducted to look into the academic and non-academic correlates of retention.

\subsection{Statement of the Problem}

This study aimed to determine the academic and non-academic correlates of the student retention. Specifically, it sought to answer the following questions:

1. What are the demographic profiles of students who had withdrawn from the university in terms of gender, program enrolled, marital status, and employment status? 
2. What are the top academic or non-academic correlates of student retention?

3. What are the least cited academic or non-academic correlates of student retention?

\subsection{Theoretical Framework}

In researches about academic retention, Tinto's model is the most commonly-used model which provides providing a theoretical framework to understand the students' behaviors. Tinto's theory states that "the decision to 'drop out' arises from a combination of student characteristics and the extent of their academic, environmental and social integration in an institution". Tinto's original model is composed of five aspects with concepts interrelating to identify a student's decision to withdraw. However, the three primary principles of Tinto's model include processes in which HEIs were dedicated to serve the students, that they were committed to the education of everyone and not just for some and lastly, that they were steadfast in providing support in social and educational communities in which all students are members (Tinto, 2011).

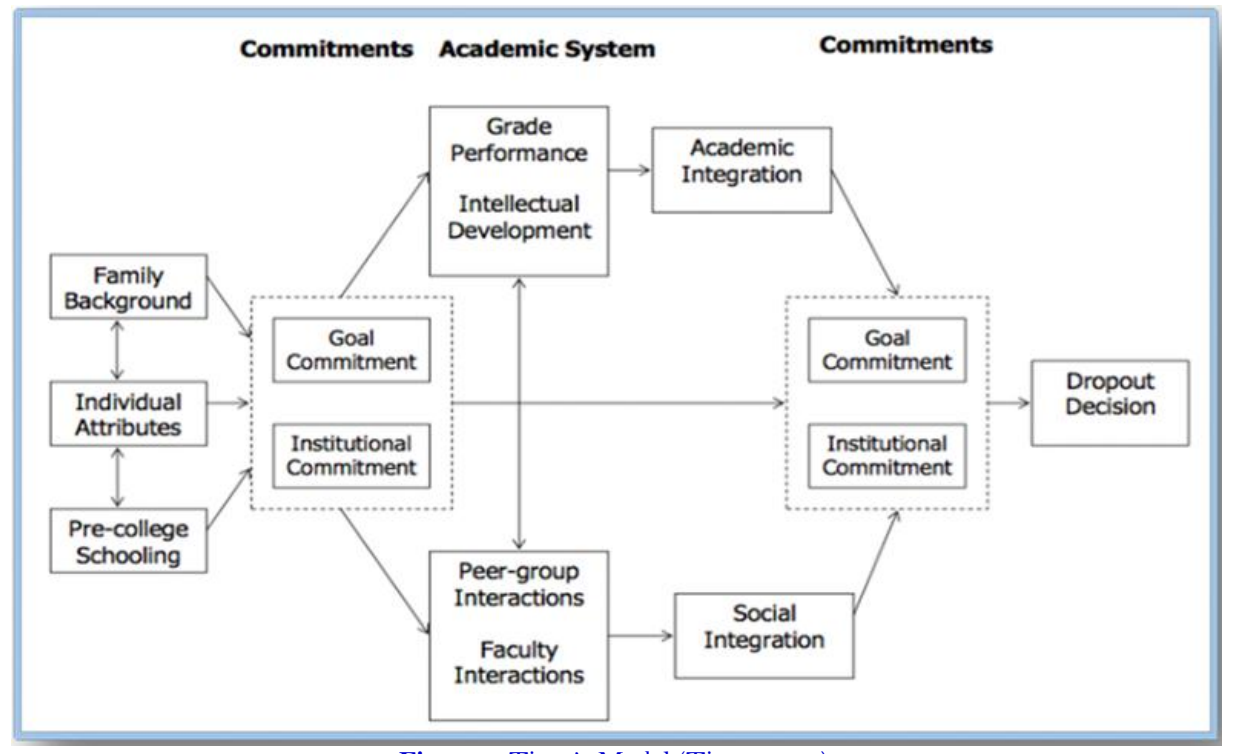

Figure1. Tinto’s Model (Tinto, 2011).

The model illustrates that "adjustment, difficulty, incongruence, isolation, finances, learning, and external obligations or commitments are factors that may push students to discontinue their studies". Moreover, Tinto noted that "the stronger the individual's level of social and academic integration, the greater his or her subsequent commitment to the institution and to the goal of college graduation". Hence, the model posits that "students' withdrawal from institutions is a result of longitudinal process of interactions between an individual with given attributes, skills, financial resources, prior educational experiences, dispositions (intentions and commitments) and integration with other members of the academic and social systems of the institution. Students' entry commitment affects the extent of their social and academic interaction within a learning institution, and the extent of their integration, which in turn has an impact on their goals and institutional commitment.

\section{RESEARCH METHODOLOGY}

The researchers verified the reasons of 443 sample respondents, composed of students who had withdrawn or discontinued their studies at the selected HEI. Academic and non-academic correlates of student retention were identified through the reasons provided by the students' Withdrawal/Dropping Out Forms which are available at the Registrar's Office. Moreover, telephone calls were made to further discuss the reasons for leaving the university. The response options were classified into three areas: academic issues, financial issues, and "other" issues. The academic and financial issues were further divided into student-related, which is attributable to the students and 
institutional-related which is attributable to the reasons related to the HEI. Furthermore, the "other" issues was divided to career and personal issues of the students.

Then, a checklist used to indicate the information gathered from the documents and from the telephone interviews. The checklist was adapted from the What Works in Student Retention? Fourth National Survey Report for All Colleges and Universities (ACT, 2010). Upon retrieval of the needed information, the data were processed, analyzed and interpreted according to the requirements of the problems. For descriptive statistics tools, mean and rank were used.

\section{RESULTS AND DISCUSSIONS}

The figures below show the profile of the students who had withdrawn or discontinued their studies in the university from the Academic Year 2010-2011 to the Academic Year 2016-2017.

\subsection{Participants According To Gender}

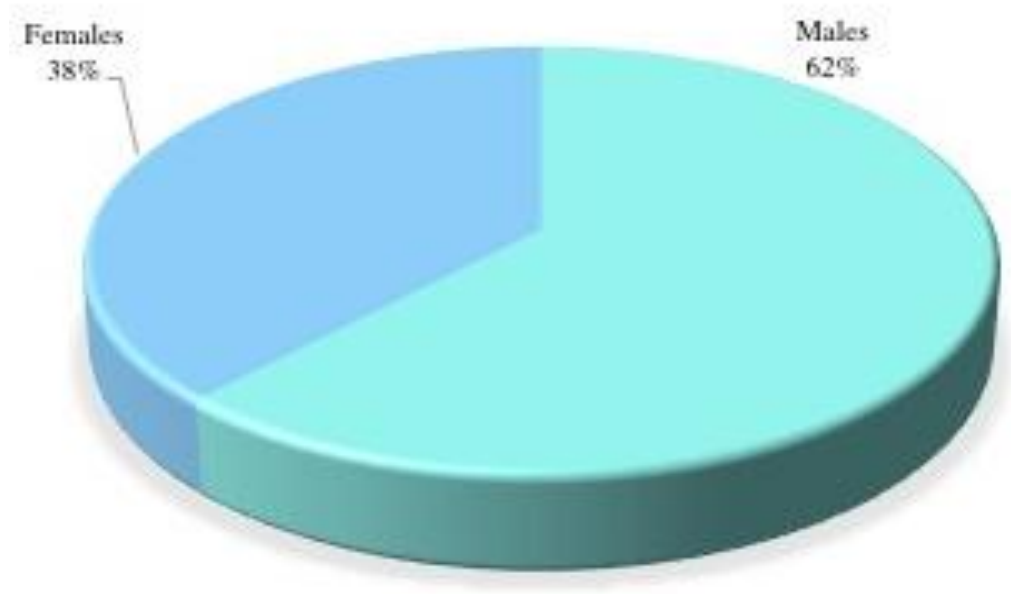

Figure-2. Participants according to gender.

Figure 2 shows that there were more males $(62 \%)$ who had withdrawn or discontinued their studies than females $(38 \%)$.

\subsection{Participants According to Program Enrolled}

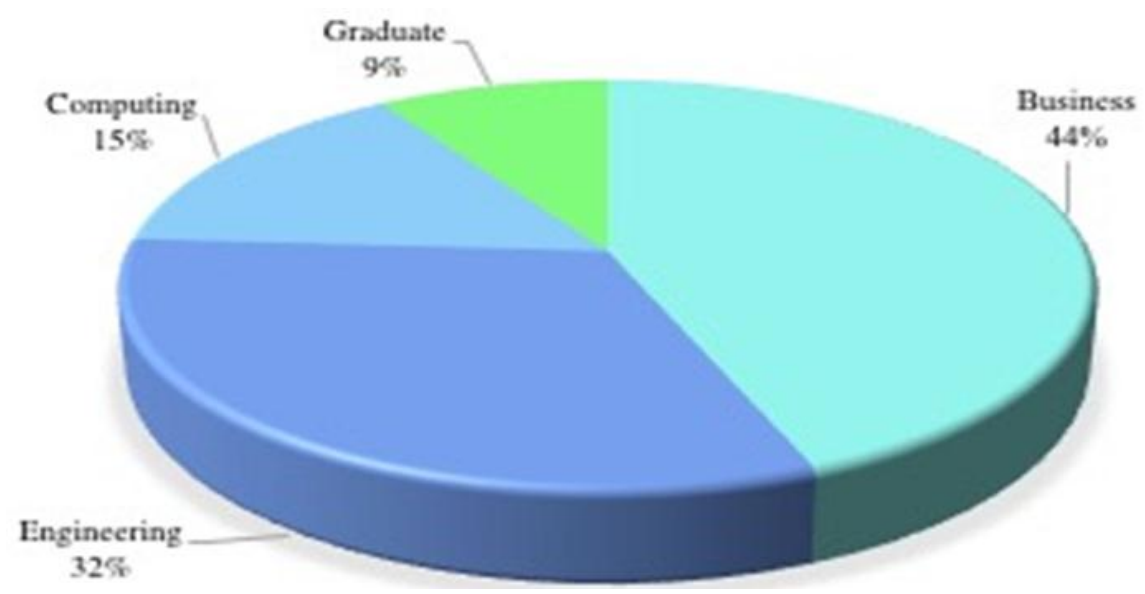

Figure-3. Participants according to program enrolled.

Figure 3 indicates that majority of the students who had withdrawn or discontinued their studies were from the 
business program (44\%), followed by the engineering (32\%), computing (15\%), and lastly, the graduate students $(9 \%)$.

\subsection{Participants According to Marital Status}

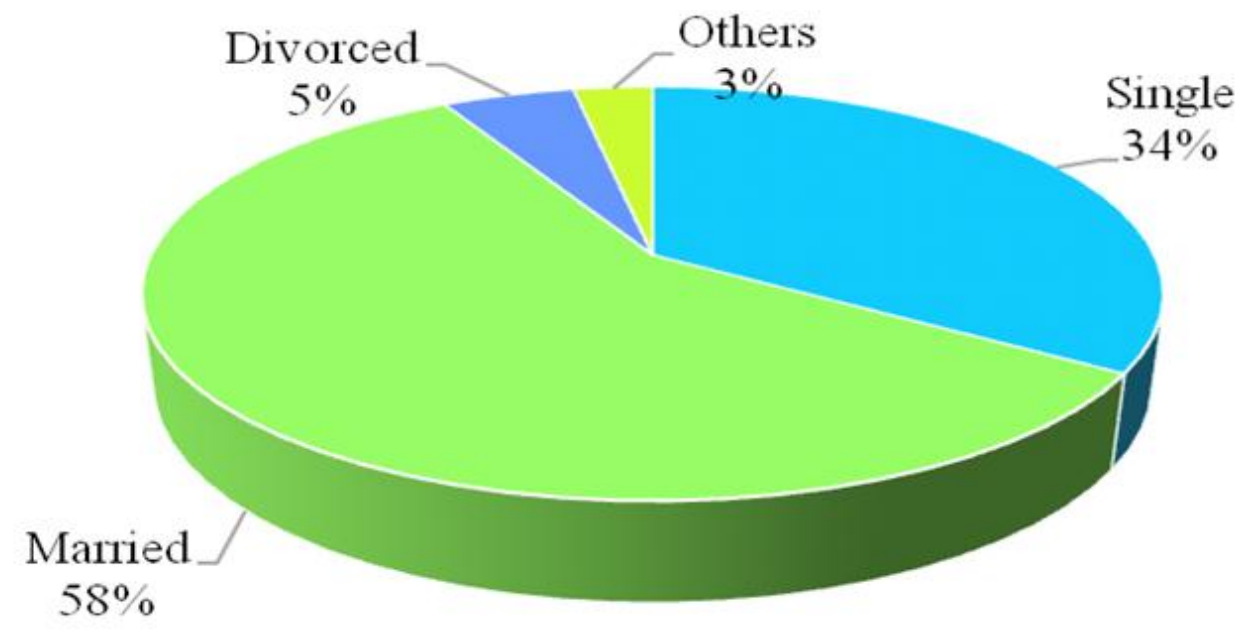

Figure-4. Participants according to marital status.

Figure 4 shows the marital status of students who had withdrawn or discontinued their studies. Among which, $58 \%$ are married, $34 \%$ are single, $5 \%$ for those who were divorced, and $3 \%$ did not state their marital status.

\subsection{Participants According to Employment Status}

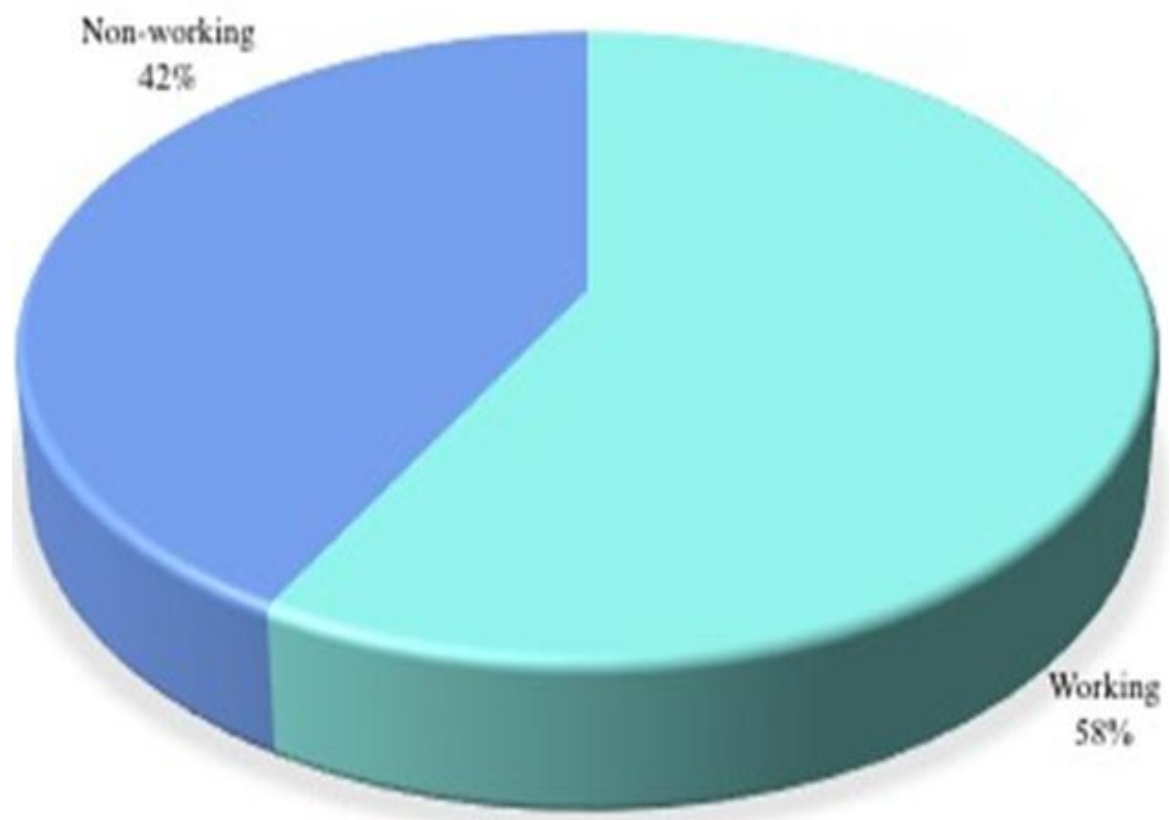

Figure-5. Participants according to employment status.

As shown in Figure 5, majority of students who had withdrawn or discontinued their studies are working students $(58 \%)$ and $42 \%$ are non-working. 


\subsection{Academic and Non-academic Correlates of Student Retention}

Table-1. Academic and Non-academic Correlates of Student Retention

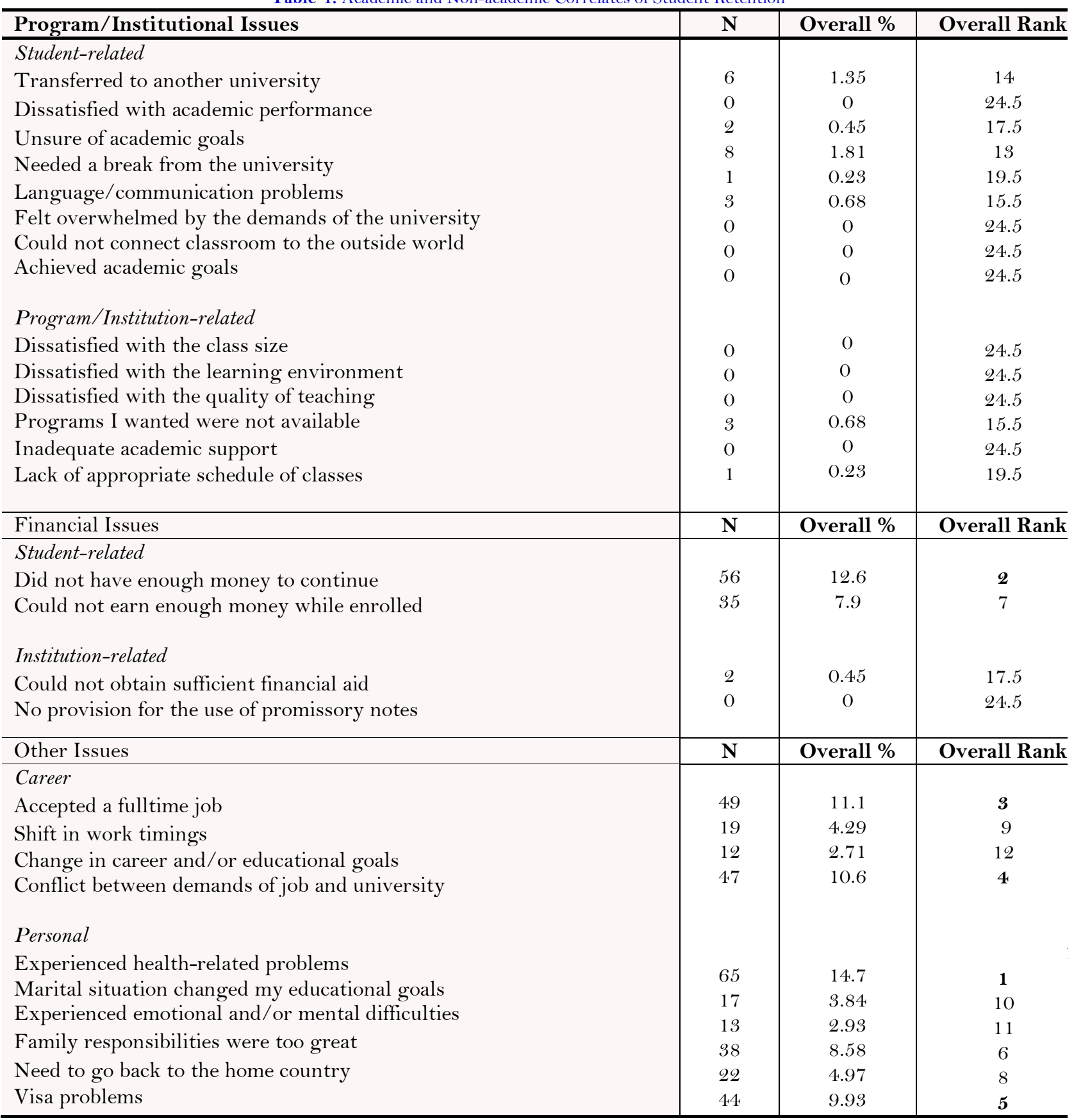

Table 1 presents the number of responses given for each academic or non-academic correlate of student retention, along with the percentage of responses and ranks. The data show that over all, students had withdrawn or discontinued their studies because of "other" issues, particularly, career and personal issues, than for program/institutional or financial issues. Among the reasons cited for leaving the university, the top five are: 1. experienced health-related problems; 2. did not have enough money to continue; accepted a fulltime job; 4 . conflict between demands of job and university; and 5. visa problems.

Results of the present investigation are concurred by the study conducted in Australia which found out that students leave the university because of personal difficulties in which health, finance, and work issues have been emphasized (King, 2017). Moreover, Yamnikar (2006) noted that some students withdraw if their employment 
conditions change.

On the other hand, results of this research differ from the study of Marsh (2014) which revealed that students withdraw from the university because of isolation. The non-academic correlates of student retention of the university also vary from the study of Canadian universities which demonstrated that academic advising; social connectedness; involvement and engagement; faculty and staff approachability, business procedures; learning experiences; and student support services play a major role in student retention (Roberts \& Styron, 2010).

The correlates least cited of student retention were on the program/institutional issues such as: 1. dissatisfied with academic performance; 2.could not connect classroom to the outside world;3. achieved academic goals; 4 . dissatisfied with the class size; 5. dissatisfied with the learning environment; 6. dissatisfied with the quality of teaching; and 7. inadequate academic support. In fact, none of the students who had withdrawn noted these as factors why they left the University. The results are supported by Kinzie and Kuh (2004) who underscored that student success is fostered by educationally effective institutions. Effective and efficient collaboration among faculty, staff, and administration in developing effectual initiatives to provide for student success and retain students at this institution.

In addition, the university has various support activities to support student-at-risk students. This also corresponds to what Vedder (2015) has advanced that many institutions seek to develop plans for improving student retention rates by focusing on at-risk student populations or implementing an institution-wide strategy to improve student retention rates.

\section{CONCLUSIONS}

Based on the findings, the following conclusions are drawn:

1. Majority of students who had withdrawn from the university are males. In terms of program enrolled, there are many business students who dropped out from the university, followed by the engineering, computing, and lastly, the graduate students. In terms of marital status, most who dropped out are married, followed by single, divorced, and others who did not mention their status. On the other hand, there were more working students who had withdrawn from the University compared to non-working students.

2. Among the reasons cited for leaving the HEI, the top five are experienced health-related problems, did not have enough money to continue, and accepted a fulltime job, conflict between demands of job and university, and visa problems.

3. Reasons that were not cited at all are on the program/institutional issues such as dissatisfied with academic performance, could not connect classroom to the outside world, achieved academic goals, dissatisfied with the class size, dissatisfied with the learning environment, dissatisfied with the quality of teaching, and inadequate academic support.

\section{RECOMMENDATIONS}

1. The university, through its Office of the Student Affairs, should strengthen its intervention programs that would aid students, especially those who are at-risk and those who face academic or non-academic issues. Since none of the correlates of student retention were attributed to said HEI and its programs, the top management and the senior management may consider other interventions which could help address the main issues that forced students to withdraw from the university.

2. Convocation, orientation, induction program, and seminars for the freshmen students are deemed significant to acclimatize them to their new academic environment. Hence, these activities have to give substantial information, especially to the new or transferred students in order for them to be aware of the University's programs and activities that could help them in their curricular, co-curricular, and extra- curricular undertakings. 
3. The academic community should continue to create a conducive and active learning environment that support students' holistic development.

4. Researchers may delve into other aspects that contribute to student retention.

Funding: This study received no specific financial support.

Competing Interests: The authors declare that they have no competing interests.

Acknowledgement: Both authors contributed equally to the conception and design of the study.

\section{REFERENCES}

ACT. (2010). What works in student retention? Fourth national survey report for all colleges and universities. Retrieved from https://files.eric.ed.gov.

King, M. (2017). Student retention and success. Retrieved from https:// www.flinders.edu.au

Kinzie, J., \& Kuh, G. D. (2004). Going DEEP: Learning from campuses that share responsibility for student success. About Campus, 9(5), 2-8.Available at: https://doi.org/10.1002/abc.105.

Marsh, G. (2014). Institutional characteristics and student retention in public 4-year colleges and universities. Journal of College Student Retention: Research, Theory \& Practice, 16(1), 127-151.Available at: https://doi.org/10.2190/cs.16.1.g.

Roberts, J., \& Styron, R. (2010). Student satisfaction and persistence: Factors vital to student retention. Research in Higher Education Journal, 6, 1-18.

Sagenmüller, I. (2018). Main factors that affect student retention in higher education. Retrieved from https:// www.uplanner.com.

Tinto, V. (2011). Promoting student completion one class at a time. Pell Institute for the Student of Opportunity in Higher Education. Retrieved from http://www.acenet.edu.

Vedder. (2015). 25 ways to reduce the cost of college. Center for College Affordability and Productivity (NJ1). Retieved from: https://eric.ed.gov/?id=ED536144.

Yamnikar, J. A. (2006). Increasing retention rates of new students by improving the induction process. HEA Centre for Education in the Built Environment Case Study, $21(9), 07$.

Views and opinions expressed in this article are the views and opinions of the author(s), International Journal of Publication and Social Studies shall not be responsible or answerable for any loss, damage or liability etc. caused in relation to/arising out of the use of the content. 